\title{
Non-invasive grading of aortic regurgitation by Doppler ultrasonography
}

\author{
ANDREAS HOFFMANN, MATTHIAS PFISTERER, PETER STULZ, \\ HANS E SCHMITT, FELIX BURKART, DIETER BURCKHARDT \\ From the Division of Cardiology, University Hospital, Basle, Switzerland
}

SUMMARY Doppler ultrasound without concomitant echocardiographic imaging was used to grade isolated aortic regurgitation in 21 patients. The severity of aortic regurgitation was subsequently graded (from 0 to IV) angiographically.

A $2 \mathrm{MHz}$ continuous wave Doppler transducer was placed over the apex of the heart and the beam was aimed parallel to the mitral flow by means of acoustic guidance. Mitral pressure half time was calculated from the analogue maximum velocity tracing and it was $\leqslant 60 \mathrm{~ms}$ in 10 controls; $50-120 \mathrm{~ms}$ in five patients with grade II, $120-160 \mathrm{~ms}$ in nine patients with grade III, and $\geqslant 160 \mathrm{~ms}$ in seven patients with grade IV aortic regurgitation.

These results indicate that a semi-quantitative grading of aortic regurgitation may be obtained non-invasively with non-imaging Doppler ultrasonography in patients without concomitant mitral valve disease.

In patients with severe aortic regurgitation the presystolic murmur described by Austin Flint in 1862 presumably results from impairment of mitral flow by the aortic regurgitant jet impinging on the mitral valve. ${ }^{1}$ Because intracardiac blood flow can be measured non-invasively by Doppler ultrasonography, ${ }^{2}$ we investigated the possibility of predicting the severity of aortic regurgitation on the basis of mitral flow measured by the Doppler method.

\section{Patients and methods}

\section{PATIENTS}

We studied 21 patients with aortic regurgitation (15 men, 6 women, aged 27-74 years). Patients with rheumatic mitral valve disease were excluded by echocardiography. All patients underwent subsequent left heart catheterisation and biplane aortography for visual grading of aortic regurgitation by an independent observer (grade 0 , no regurgitation; grade I, faint regurgitation; grade II, frank regurgitation without accumulation of contrast material within the left ventricle; grade III, regurgitation and accumulation of contrast; grade IV, free regurgitation with immediate opacification of the

Requests for reprints to Dr Andreas Hoffmann, Division of Cardi- . ology, University Hospital, 4031 Basle, Switzerland.

Accepted for publication 22 October 1985 entire left ventricle). We also studied 10 controls without valvar heart disease.

\section{DOPPLER TECHNIQUE}

A $2 \mathrm{MHz}$ continuous wave ultrasound transducer without imaging capability was placed over the apex of the heart, with the ultrasonic beam aimed towards the mitral orifice and kept parallel with the mitral blood flow by means of acoustic guidance. The Doppler instrument (Pedof, Vingmed, Oslo) is equipped with frequency estimators, providing analogue outputs of non-directional maximum flow velocity $\left(V_{\max }\right)$ and directional mean velocity $\left(V_{\text {mean }}\right)$. When the typical diastolic audiosignal of mitral flow was heard, simultaneous recordings of electrocardiogram, $V_{\text {mean }}$, and $V_{\max }$ were made at 50 $\mathrm{mm} / \mathrm{s}$ paper speed. The mitral pressure half time $(t / 2)$ was determined from the $V_{\max }$ recordings-that is the time required for $V_{\max }$ at its peak diastolic value (A) to reach the point $B=A / \sqrt{2}$ (Fig. 1). $t / 2$ has been shown to correlate inversely with the area of the mitral valve orifice in patients in whom mitral flow is impaired by mitral stenosis. ${ }^{23}$

STATISTICAL ANALYSIS

Doppler and angiographic data were compared by the non-parametric rank correlation method of Kendall. ${ }^{4}$ 

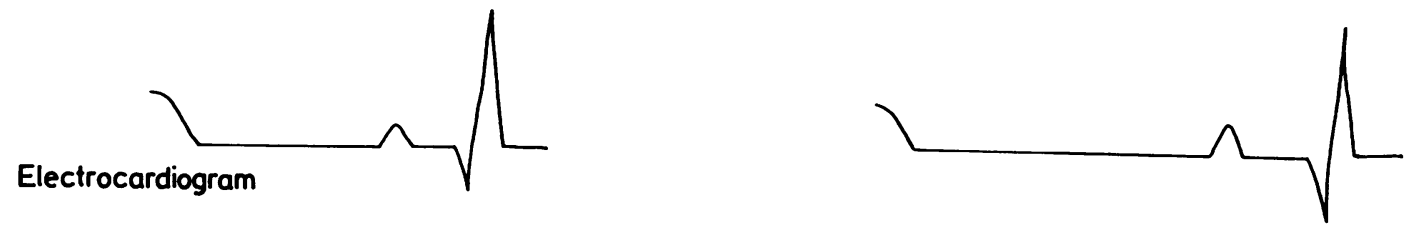

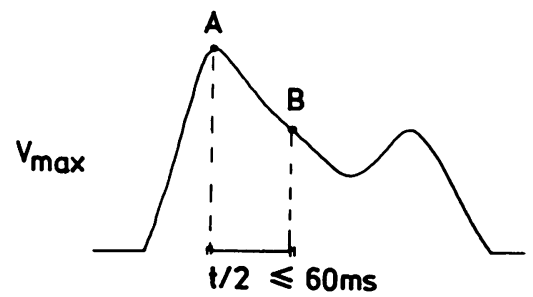

Normal

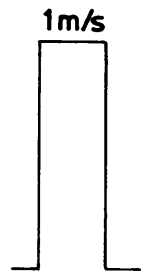

$\mathrm{B}=\frac{\mathrm{A}}{\sqrt{2}}$

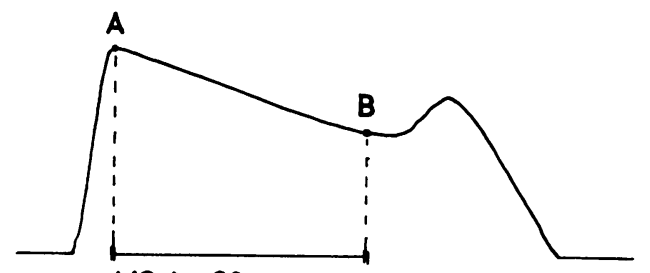

$\mathrm{t} / 2>60 \mathrm{~ms}$

Fig. 1 Schematic representation of normal mitral flow (left) and prolongation of mitral pressure half time (t/2) (right). $V_{\text {max }}$, maximum flow velocity.

\section{Results}

Mitral pressure half time was $\leqslant 60 \mathrm{~ms}$ in all controls, whereas it was $50-120 \mathrm{~ms}$ in the five patients with grade II aortic regurgitation; $120-160 \mathrm{~ms}$ in the nine patients with grade III aortic regurgitation; and $\geqslant 160 \mathrm{~ms}$ in the seven patients with grade IV aortic regurgitation (Figs. 2 and 3). There was a highly significant correlation between the angiographic and Doppler grading (Kendall's rank correlation test, $\mathrm{p}<0.001$ ). Left ventricular end diastolic pressures ranged from $8 \mathrm{~mm} \mathrm{Hg}$ to $44 \mathrm{~mm} \mathrm{Hg}$. There was no correlation. between $t / 2$ and left ventricular end diastolic pressure. An Austin Flint murmur was detected clinically in eight of 16 patients with grade III or IV aortic regurgitation.

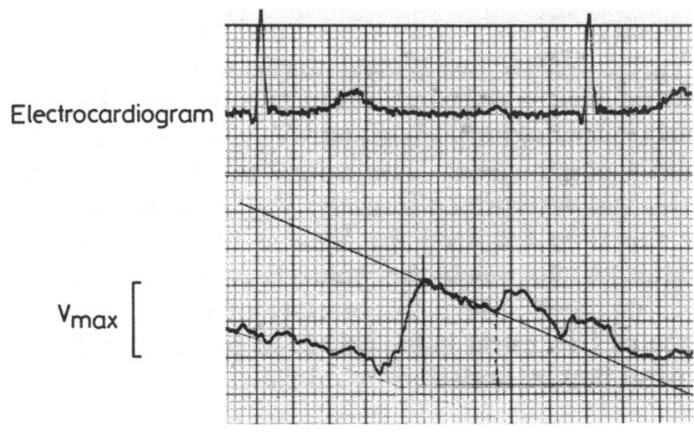

Fig. 2 Prolonged mitral pressure half time (200 ms) as measured on the mitral maximum flow velocity curve in a patient with severe aortic regurgitation (angiographic grade IV) (calibration $=1 \mathrm{~m} / \mathrm{s} ;$ paper speed $=50 \mathrm{~mm} / \mathrm{s}$ ).

\section{Discussion}

Non-invasive grading of aortic regurgitation has been unrewarding in the past. Because the aortic regurgitant jet can be detected directly by Doppler

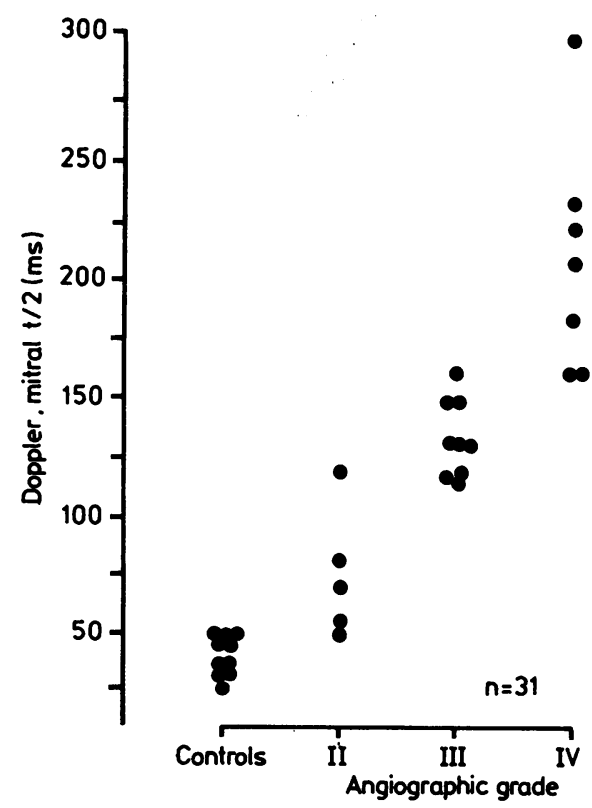

Fig. 3 Comparison of mitral pressure half time $(t / 2)$ as measured by the non-invasive Doppler method and angiographic grade of aortic regurgitation in 21 patients with aortic regurgitation and in 10 controls $(p<0.001$ by Kendall's rank correlation test). 
ultrasound techniques there have been several attempts at quantitation. Boughner calculated a regurgitant fraction from planimetric comparison of forward-to-reverse flow curves. ${ }^{5} \mathrm{~A}$ similar approach was used by Sequeira and Watt ${ }^{6}$ and by Quinones $e t$ $a l{ }^{7}$ whereas Diebold et al reported the use of a forward-to-reverse velocity index. ${ }^{8}$ The usefulness of these methods is limited primarily by the considerable overlap of data and by the difficulty of obtaining adequate simultaneous tracings of systolic and diastolic flow curves. Jenni et al showed that the use of multiple gates (pulsed wave mode) provides a better basis for measurement of flow. ${ }^{9}$ This technique, however, is experimental. Ciobanu et al reported a different technique with mapping of the left ventricular outflow tract to detect the presence of aortic regurgitant flow, and the results of this method accorded well with angiographic grading. ${ }^{10}$ Their method needs to be confirmed.

We used the simple and inexpensive technique of continuous wave Doppler without concomitant echocardiographic imaging. The impairment of diastolic flow through the mitral orifice was used as a measure of aortic regurgitation. Prediction of the angiographic severity of aortic regurgitation by this method was good (Fig. 3). Most authorities agree that though there may be early closure of the mitral valve in cases of acute aortic regurgitation, this is not likely to be responsible for the Flint murmur in all cases. The Flint murmur seems to arise rather as a result of turbulence generated between mitral and aortic flows in diastole. ${ }^{11}$

Alteration of mitral flow can only be used as a measure of aortic regurgitation in patients without mitral valve disease because in mitral stenosis the duration of $t / 2$ is inversely related to the mitral valve area. ${ }^{3}$ Also in patients with severe aortic regurgitation clear recordings of mitral flow are sometimes difficult to obtain because of excessive turbulence. Indeed, mitral $\mathrm{V}_{\max }$ tracings were difficult to record in some of our patients. Normal mitral flow does not entirely rule out important aortic regurgitation because the regurgitant jet may be diverted more towards the left ventricular posterior wall and thus avoid the mitral inflow. Care must also be taken to avoid the aortic regurgitant jet. This is accomplished by searching for the typical biphasic pattern of mitral flow with low velocity.

An alternative explanation for prolongation of $t / 2$ in patients with aortic regurgitation is that the increase in left ventricular end diastolic pressure impedes left atrial emptying. The relation between $t / 2$ and end diastolic pressure in our patients, however, was less obvious than that between $t / 2$ and aortic regurgitation grade, and $t / 2$ was normal in patients with raised end diastolic pressures due to congestive heart failure of non-valvar origin.

In conclusion, non-invasive grading of aortic regurgitation by measurement of mitral flow impairment with a simple continuous wave Doppler ultrasound method without simultaneous imaging is feasible in patients without concomitant mitral valve disease.

\section{References}

1 Flint A. On cardiac murmurs. Am $\mathcal{F}$ Med Sci 1862; 44: 29-54.

2 Hatle L, Angelsen B. Doppler ultrasound in cardiology. 2nd ed. Philadelphia: Lea and Febiger, 1985.

3 Robson DJ, Flaxman JC. Measurement of the end diastolic pressure gradient and mitral valve area in mitral stenosis by Doppler ultrasound. Eur Heart $\mathcal{F}$ 1984; 5: 660-7.

4 Kendall MG. Rank correlation methods. 4th ed. London: Griffin, 1970.

5 Boughner DR. Assessment of aortic insufficiency by transcutaneous Doppler ultrasound. Circulation 1975; 52: 874-9.

6 Sequeira RF, Watt I. Assessment of aortic regurgitation by transcutaneous aortovelography [Abstract]. Br Heart f 1977; 39: 929.

7 Quinones MA, Young JB, Waggoner AD, Ostojic MC, Ribeiro LGT, Miller RR. Assessment of pulsed Doppler echocardiography in detection and quantification of aortic and mitral regurgitation. $\mathrm{Br}$ Heart F 1980; 44: 612-20.

8 Diebold B, Peronneau P, Blanchard D, et al. Noninvasive quantification of aortic regurgitation by Doppler echocardiography. $B r$ Heart $\mathcal{f}$ 1983; 49: 167-73.

9 Jenni R, Hübscher W, Casty M, Anliker M, Krayenbühl HP. Quantitation of aortic regurgitation by a percutaneous 128-channel digital Doppler ultrasound instrument. In: Lancée CT, ed. Echocardiology. The Hague: $M$ Nijhoff, 1979: 241-3.

10 Ciobanu M, Abbasi AS, Allen M, Hermer A, Spellberg R. Pulsed Doppler echocardiography in the diagnosis and estimation of severity of aortic insufficiency. $A m \mathcal{F}$ Cardiol 1982; 49: 339-43.

11 Reddy PS, Curtiss EI, Salerni R, et al. Sound pressure correlates of the Austin Flint murmur. Circulation 1976; 53: 210-7. 